\title{
MOBILIDADE URBANA: UMA QUESTÃO EM ABERTO NO NOVO PLANO DIRETOR DA CIDADE DE SÃO PAULO
}

\author{
URBAN MOBILITY: AN OPEN QUESTION IN THE NEW MASTER PLAN OF SÃO PAULO CITY
}

\section{AYUB, ULISSES}

Mestre na área de Arquitetura e Urbanismo pela Universidade São Judas Tadeu - SP. (2016); Gestor de Transporte e Tráfego na Companhia de Engenharia de Tráfego em São Paulo - CET SP (1991-atual); Arquiteto do Departamento de Pólos Geradores de Tráfego na Companhia de Engenharia de Tráfego - CET SP; Email: ulissesone@terra.com.br

\section{KOURY, ANA PAULA}

Doutora em Arquitetura e Urbanismo pela FAU/USP (2005); Professora na graduação e pós graduação (mestrado) na Universidade São Judas Tadeu - SP; Fulbright visiting professor na Bernard and Anne Spitzer School of Architecture no The City College of New York; (2016)

Email: apkoury@gmail.com

\section{RESUMO}

Esta análise pretende discutir o tema da mobilidade urbana na cidade de São Paulo. Especialmente o sistema de mobilidade relacionado à geração e atração de viagens veiculares relacionadas ao transporte público e veículos particulares. O tema será abordado em diferentes escalas e procurará caracterizar seu desempenho atual e uma estimativa futura, para com isso compreender a interface que ocorre com as políticas urbanas, os planos de recuperação urbana e os modelos de mobilidade. O estudo do sistema de mobilidade permite entender um dos mais importantes mecanismos de crescimento da metrópole bem como a sua interface com o planejamento urbano. Apresentaremos as diretrizes urbanísticas do novo Plano Diretor Estratégico de São Paulo analisando as suas estratégias para o desenvolvimento da cidade, e exemplificando a análise com situações urbanas conflitantes.

PALAVRAS-CHAVE: mobilidade; planejamento urbano; transporte e plano diretor.

\section{ABSTRACT}

This analysis aims to discuss the issue of urban mobility in the city of São Paulo. In particular, aims to discuss the mobility system related to the generation and attraction of vehicular travelling, associated both to public transportation and private vehicles. The subject will be addressed at different levels and will characterize the current performance and a future valuation, in order to understand the interface with urban policies, plans for urban regeneration and mobility models. Through the study of the mobility system we are able to understand one of the main growth mechanisms of the metropolis and its interface with urban planning. We will present the urban planning guidelines of the new Strategic Master Plan of São Paulo City analyzing its strategies for the city development, exemplifying the analysis with conflicting urban situations.

KEY-WORDS: mobility, urban planning, transportation and master plan 


\section{MOBILIDADE: UMA QUESTÃO PARA O PLANEJAMENTO URBANO}

\section{Ponto de partida: A cidade}

São Paulo é uma cidade de muitos contrastes. Esta afirmação é mais do que um clichê. Através de uma atenta observação, podemos constatar que em regiões estratégicas da cidade, como as regiões envoltórias da Av. Paulista e da Av. Faria Lima/Vila Olímpia, está concentrada a maioria das empresas e serviços que movimentam a economia local e até mesmo, pode-se dizer, nacional. Em contrapartida, nas regiões mais periféricas da cidade, localizam-se aglomerados urbanos com milhares de pessoas vivendo em favelas ou assentamentos irregulares em terras invadidas.

Flávio Villaça (1998, p.141), em seu importante estudo sobre o espaço intra-urbano nas cidades, explica a relação entre localização e segregação espacial. Embora as condições de urbanização das periferias tenham melhorado consideravelmente desde a publicação do estudo, ainda hoje podemos constatar uma grande diferença no valor dos terrenos. Em bairros nobres localizados no chamado quadrante centro sul da cidade, como o Itaim Bibi e o Jardim Paulistano, as médias do metro quadrado $\left(\mathrm{m}^{2}\right)$ de construção valem $\mathrm{R} \$ 12.978,00$ e $\mathrm{R} \$ 16.160,00$ respectivamente, conforme anotado no índice FipeZap de julho de 2016. Em bairros mais afastados do centro, com valores médios por metro quadrado muito menor do que no glamoroso Jardim Paulistano, como os bairros do Itaim Paulista e Capão Redondo, as médias do m² são de $\mathrm{R} \$ 3.763,00$ e $\mathrm{R} \$ 4.108,00$ respectivamente conforme anotado no índice FipeZap de julho de 2016. Também nas periferias a especulação imobiliária inflaciona os aluguéis deixando milhares de famílias sem ter onde morar, empurrando-as cada vez mais para áreas mais distantes e menos urbanizadas.

Estes dois padrões de urbanidade de São Paulo definiram no quadro atual da cidade, duas regiões distintas em suas ocupações; uma "consolidada" e outra "em situação de vulnerabilidade". A região consolidada é composta pelos bairros majoritariamente de uso residencial ou de uso misto, ao redor do centro da cidade, nos quais se concentra a moradia de uma classe mais abastada e das classes médias. Também fazem parte desta região consolidada, as centralidades que se formaram ao longo da evolução urbana da cidade e onde se localizam os empregos formais. A região "em situação de vulnerabilidade", ao contrário, concentra as áreas que possuem baixas taxas de emprego, poucas áreas verdes, escassez de equipamentos e serviços públicos e freqüentemente são mal servidas pelas redes de transporte público.

Assim, podemos basicamente apresentar uma pequena parcela de um cenário da cidade, em que o crescimento habitacional ocorre nos bairros extremos e, em contrapartida, verifica-se paralelamente um concomitante aumento dos postos de trabalho e oferta de serviços na região centro-oeste, a qual se situa em área longínqua da região de moradia da maior parte da população, que se caracteriza por ser apenas fornecedora de mão de obra.

Dessa forma, a cidade se apresenta ao cidadão como um fenômeno caótico em função da desigualdade na estrutura de ocupação das várias regiões da cidade e conseqüentemente do modo de mobilidade que a população necessita. Essa dualidade que caracteriza a percepção da cidade de São Paulo também é encontrada em outras cidades do Brasil que passaram por um processo de urbanização sem que fosse possível incluir a parte principal da população urbana em um sistema formal de trabalho compatível com a inclusão à cidade formal.

\section{A ocupação urbana e seu relacionamento com a mobilidade e o transporte}

A maioria dos especialistas que estudam o tema da mobilidade urbana afirma que, para compreender a crise dos transportes nas cidades, devemos analisar detalhadamente as relações entre os locais de moradia e trabalho da população; as regras de uso e ocupação do solo; as modalidades de transportes e as condições de infraestrutura do viário. Ou seja, uma abordagem não setorial dos elementos da política urbana, aliada à construção de um sistema de variáveis de planejamento e intervenção no qual, ao invés da abordagem analítica dos elementos do planejamento, as inter-relações entre os fatores sejam enfatizadas. São Paulo é uma cidade de grandes dimensões territoriais, 1.521,110 km², e esse é um motivo para que boa parte da 
população entenda que é necessário estar motorizado para ser capaz de circular livremente e percorrer as grandes distancias metropolitanas com rapidez, conforto e segurança.

A mobilidade urbana é medida pelo desempenho do sistema viário, através de pesquisa sistemática de monitoração da fluidez nas principais vias da cidade. O objetivo é possuir uma fonte de consulta de dados e informações de volume e velocidade necessários para subsidiar os estudos de engenharia de tráfego.

Segundo dados do Relatório 2014 - Operação Horário de Pico - $17^{\circ}$ avaliação (2015), da Companhia de Engenharia de Tráfego de São Paulo, entre 2008 e 2014, a média anual de lentidão por as vias da cidade, no pico da manhã (7:00hs as 9:00hs), gira em torno dos 89 km e no pico da tarde (17:00hs as 19:00hs) em torno dos $141 \mathrm{~km}$.

Tem-se verificado congestionamentos com lentidões significativas em corredores e vias estruturais localizadas em áreas distantes da área do centro expandido e de vias consolidadas com históricos de congestionamentos. Além disso, hoje os congestionamentos acontecem em horários que antecedem os horários de pico históricos registrados na cidade. Segundo os dados do Relatório 2014 - Operação Horário de Pico - $17^{\circ}$ avaliação (2015), da Companhia de Engenharia de Tráfego de São Paulo o tempo médio gasto em deslocamentos gira em torno de 2 horas. Com esses dados os técnicos especializados em transporte e tráfego possuem condições de esboçar um cenário futuro prevendo os sentidos de deslocamentos pela cidade.

Conforme anotado no Relatório 2014 - Operação Horário de Pico - $17^{\circ}$ avaliação (2015), da Companhia de Engenharia de Tráfego de São Paulo, a taxa de veículos por habitantes é a indicada na tabela 1, na qual pode-se constatar que a motorização dos habitantes da cidade tem aumentado ano a ano. Esses resultados obtidos pela Cia. de Engenharia de Tráfego de São Paulo são elucidados nas análises formuladas pelos especialistas Mauricio Moreira e Anísio Dourado (2013) no estudo "A taxa de motorização nas cidades brasileiras e a questão da mobilidade urbana". Os autores afirmam que várias causas podem explicar os expressivos aumentos na frota de veículos em circulação. Entre as causas que mais se ressaltam estão a precariedade do transporte público de passageiros, a intenção dos habitantes adotarem o transporte individual como solução de mobilidade urbana e o maior poder aquisitivo registrado nos últimos anos.

Tabela 1 - Relatório 2014 - Operação Horário de Pico - $17^{\circ}$ avaliação (2015)

\begin{tabular}{|c|l|l|c|}
\hline ANO & $\begin{array}{l}\text { População do Município } \\
\text { (SEADE-SP) }\end{array}$ & $\begin{array}{l}\text { Frota anual de veículos } \\
\text { (DETRAN-SP) }\end{array}$ & Veículos por 100 habitantes \\
\hline 2008 & 11.093 .746 & 6.369 .581 & 57 \\
\hline 2009 & 11.168 .194 & 6.705 .024 & 60 \\
\hline 2010 & 11.245 .983 & 6.954 .750 & 62 \\
\hline 2011 & 11.312 .351 & 7.186 .724 & 64 \\
\hline 2012 & 11.379 .114 & 7.363 .210 & 65 \\
\hline 2013 & 11.446 .275 & 7.577 .216 & 69 \\
\hline 2014 & 11.513 .836 & 7.887 .789 & 6 \\
\hline
\end{tabular}

Fonte: Companhia de Engenharia de Tráfego de São Paulo

Em outra importante análise do assunto, o engenheiro civil, especialista em engenharia de tráfego, Roberto S. Scaringella afirmava que "o melhor entendimento da crise da mobilidade urbana passa por uma análise mais detalhada das diversas relações entre o uso e a ocupação do solo urbano, os sistemas de transportes e a infraestrutura viária e a interação entre fator humano, veículo, via pública e meio ambiente" (2001, p.1). O autor argumentava em seus estudos que, na hipótese de haver um crescimento absurdo e repentino na verticalização da cidade, aliada a um aumento da taxa de motorização, a cidade simplesmente entraria em colapso e ninguém mais se movimentaria. Cita que desde a década de 70, gestores políticos, urbanistas e técnicos em transporte e tráfego da cidade se debruçam numa questão; quando se daria um colapso no trânsito acarretando uma crise no transporte público e individual?

Esse exemplo é uma situação hipotética, cena limite da cidade, que embora seja possível acreditar que nunca acontecerá, entretanto, serve de alerta para a piora das condições de mobilidade em certa conjuntura, esta 
sim muito verossímil em que coincidem o aumento da densidade urbana, o aumento da taxa de motorização da população e a redução de recursos e investimentos na reforma do viário e em tecnologias de transporte público de massa.

O cenário descrito pode também ser entendido historicamente dentro de um processo crescente da especialização do problema da mobilidade urbana, separando-se da disciplina de estudos urbanísticos. Segundo o arquiteto-urbanista Renato Anelli:

Os projetos viários subseqüentes (ao plano de Avenidas de Prestes Maia) abandonaram esse objetivo. O fizeram por um motivo prático: os volumes de tráfego previstos exigiam a sua separação completa do tecido urbano. Com isso, os projetos passaram a ser concebidos como questão de engenharia de tráfego e não mais como urbanismo. Inevitável que surgissem conflitos que tornam as vias de grande capacidade pontos de irradiação da degradação da cidade que deveriam servir (ANELLI, 2011, p.59).

Com o modelo de expansão horizontal inaugurado pelo Plano de Avenidas, através de uma ampla reestruturação viária da cidade, aliado à flexibilidade que os automóveis individuais e também o transporte público por rodas oferecem, ampliaram-se enormemente as fronteiras da expansão imobiliária com novas frentes para a periferia.

Com a expansão da ocupação pelas áreas periféricas pela "facilidade" de locomoção pelo transporte sobre rodas, criou-se uma desigualdade de ocupação do território que afastou ainda mais os pólos de emprego e moradia de grande parte da população.

Enquanto os empregos mantiveram-se localizados na região central, expandindo-se no sentido centrooeste e sudeste, em áreas bem consolidadas e dotadas de infraestrutura ímpar, grande parte da população migrou no sentido oposto, seja para os condomínios de alto padrão em bairros planejados, seja para as regiões mais ao sul e leste da cidade onde o custo de moradia é menor, mas revendo conceitos de localidade e principalmente, se movimentado pela cidade.

O deslocamento realizado pela população, essa analise não leva em conta o poder aquisitivo, caracteriza-se por esta combinação de localização casa-trabalho como um movimento pendular, dos bairros dormitórios para os centros detentores de serviços e empregos e vice-versa, gerando uma superlotação do sistema viário e dos transportes públicos coletivos nas grandes artérias de ligação centro-periferia.

\section{O desenvolvimento dos planos urbanísticos e sua relação com a urbanização da cidade (co- relações)}

Mas a cidade não se expandiu de forma aleatória. O debate acadêmico na área de urbanismo tem comprovado a institucionalização e a presença do planejamento urbano no crescimento da cidade (Feldman, 2005).

A cidade de São Paulo foi originada do confronto de seu intenso processo de urbanização através de vários planos urbanísticos que procuraram organizar a cidade em constante expansão. Foi na interação entre estas várias camadas de planejamento, com dinâmicas de urbanização próprias, que se formou o espaço urbano que encontramos hoje no município.

As várias iniciativas de planejamento e de processos de urbanização têm especial importância para a compreensão da evolução da cidade e sua dinâmica, isto é, como a cidade cresce e como ela se "movimenta", para qual sentido ela se dirige e como sua população se ambienta em novas regiões, como e para onde se locomove e, principalmente, como é viver nessa metrópole.

O crescimento da população da cidade de São Paulo aconteceu principalmente na segunda metade do século XX. Esquematicamente, a expansão da ocupação urbana ocorreu através do loteamento das chácaras circundantes, atendendo à demanda habitacional principalmente de migrantes e imigrantes (BRITO, 2006).

O processo de preenchimento dos vazios circundantes à cidade ocorreu com pouca orientação técnica, resultando em uma urbanização caracterizada por ter um grande contingente de moradias precárias, escassez 
de serviços públicos e demandante de longo tempo de traslado em transporte coletivo ou individual, gerando uma ocupação das vias e conseqüentemente grandes congestionamentos no deslocamento urbano.

A partir desse cenário embrionário, o tema da mobilidade urbana na cidade começa a tomar importância. Especialmente o sistema de mobilidade relacionado à geração e atração de viagens dos veículos particulares nas vias e do transporte público de massa que servem de acesso às várias regiões da cidade. O tema sempre foi e ainda é abordado em diferentes escalas de estudos para o planejamento urbano.

O arquiteto-urbanista Renato Anelli (2011), no seu livro "Plano e conformação da base da metrópole: rede de mobilidade paulistana -1960/1986", faz um trabalho histórico ao resgatar os vários planos urbanísticos que envolvem o redesenho da cidade prevendo seu futuro crescimento, sempre incorporando a questão da mobilidade e do transporte.

Inicialmente, através de um apurado dos diversos planos, temos já na década de 20 a Cia. Light propondo uma rede de metrô integrada a bondes e ônibus como forma de atender a expansão nas dimensões da cidade. Em 1930, o plano de avenidas de Prestes Maia definiria a geometria dos espaços da cidade e o meio de mobilidade que cidade adotaria no futuro. Em 1947, o prefeito da cidade, Luís Inácio de Anhaia Mello, propõe uma cidade com um núcleo central principal, rodeado por diversos outros núcleos menores e autossuficientes. Em 1949, o engenheiro norte americano Robert Moses propõe um modelo baseado no Highway Research Board, com áreas periféricas transformadas em subúrbios residenciais (ANELLI, 2011, p.19).

O economista e religioso francês Louis Joseph Lebret apresenta, entre 1956 e 1958, o estudo "Estrutura Urbana e Aglomeração Paulistana (Estruturas Atuais e Estruturas Racionais) (MICHELLY, 2013).

Em seu segundo mandato como prefeito de São Paulo em 1961, Prestes Maia propende à contratação de dois grandes planos urbanísticos: o da rede de Metrô e o Plano Urbanístico Básico (PUB) que consistia na idéia da cidade ser composta por um conjunto de pequenos núcleos urbanos autossuficientes. Em 1971, o engenheiro arquiteto Roberto Cerqueira César, elabora o PDDI - Plano Diretor de Desenvolvimento Integrado, o qual orientaria a lei de Zoneamento e o Plano de Vias Expressas para o ano de 1972. Em 1973, no governo do prefeito Figueiredo Ferraz, a prefeitura de São Paulo adere ao programa Comunidade Urbanas de Recuperação Acelerada - CURA (LUCCHESE, 2004, p.181).

Apesar dos diferentes planos terem buscado orientar o desenvolvimento de São Paulo, houve dificuldades no tratamento quanto a resolver a relação de deslocamento entre moradia, empregos e serviços. Esta relação continuou atribuída à ineficiência de um planejamento urbano apurado. As propostas e intervenções realizadas foram insuficientes frente ao conjunto das situações que dificultam a vida do morador da cidade de São Paulo, como morar e se deslocar para cobrir grandes distancias.

O processo de urbanização ocorreu sem que houvesse uma política urbana coordenada setorialmente, que aliasse grande capacidade técnica e de investimentos para conduzir uma política urbana de grandes proporções.

Sem uma política pública especifica para áreas periféricas da cidade, houve um crescimento espontâneo direcionado a uma implantação implicada com um parcelamento ilegal (clandestino) de terras, nos quais habitações precárias ou auto-construídas foram erguidas através do esforço próprio ou do sistema de mutirões em locais sem infraestrutura. (São Paulo - 1975, crescimento e pobreza)

A arquiteta-urbanista Ermínia Maricato expõe de forma muito clara as características desse tipo de ocupação urbana. Ao descrever a informalidade, ela responsabiliza o Estado que, segundo a autora, estaria atendendo aos interesses do mercado imobiliário e do capitalismo ao não reconhecer o direito dos mais pobres à terra urbana e à cidade. Em suas próprias palavras: 
Destaca-se que a ocupação ilegal de terras é informalmente consentida (ou por vezes até incentivada) pelo Estado que, entretanto, não admite o direito formal do acesso à terra e à cidade. Isso se dá por conta da articulação entre legislação, mercado e renda imobiliária (MARICATO, 1995, p.5).

Abordado por diversos autores e em diferentes períodos, como Nabil Bonduki (1997) e Rachel Rolnik (2011), podemos constatar a existência de dois padrões de urbanidades bem distintos. Um decorrente da cidade legal, com planejamento e controle oficial regulando o seu crescimento, estruturado por uma rede de mobilidade urbana e servido pela infraestrutura urbana necessária para o seu funcionamento e crescimento ordenado. E há outra cidade, clandestina e ilegal desde sua ocupação inicial, ocorrida sem planejamento prévio e deficiente em infraestrutura urbana e serviços básicos.

O sociólogo Salvatore Santagada argumenta que após o "milagre econômico" dos anos 70, temos um novo cenário no Brasil:

(...) maior endividamento externo; avanço do capital multinacional no país; maior desigualdade social e piora na distribuição de renda e concentração da propriedade rural; descontrole da inflação; e queda dos investimentos. É essa herança que irá marcar a economia brasileira ao longo dos anos 80 (SANTAGATA, 1990, p.124).

Nesse contexto, podemos buscar compreender a interface das políticas públicas com os planos de recuperação urbana juntamente com os modelos de mobilidade e identificando como o planejamento urbano afeta o padrão de moradia e mobilidade. Assim, podemos pavimentar um caminho para o entendimento de um dos mais importantes mecanismos de crescimento da metrópole.

\section{A ordenação territorial hoje: herança de um planejamento rearranjado}

Para exemplificarmos o tipo de cidade gerada pelos diferentes padrões de uso e ocupação do solo e pelos dispares e acumulativos planos de ordenação na cidade, tomemos dois distritos da cidade. Propositalmente foram escolhidos distritos que possuem características de ocupação distintas e estão localizados em pontos distantes um do outro: o Itaim Bibi e o Itaim Paulista.

O Itaim Bibi está localizado na região centro-oeste da cidade, área consolidada e com uma grande oferta de serviços e empregos. O Itaim Paulista está localizado no extremo leste da cidade, e embora não seja um bairro reconhecido como bairro dormitório, abriga uma população majoritariamente usuária de serviços e empregos localizados em outras áreas da cidade, principalmente na região centro-oeste. Essa ocupação na espacialidade do território tem um preço que a população paga para encontrar uma maior oferta de serviços e de possuir um emprego; o de percorrer todos os dias aproximadamente $36 \mathrm{~km}$ da região de origem até o destino.

O distrito do Itaim Bibi se constitui pela verticalização e adensamento de seu território $\left(9.351\right.$ hab. $/ \mathrm{km}^{2}$ fonte PMSP), por conta do grande número de modernos edifícios construídos e de um viário consolidado e legalmente distribuído e fiscalizado. Recebe todo tipo de incrementos físicos e financeiros através do setor público e privado, e até em parcerias público/privado. Essas associações têm como objetivo a melhora na ocupação do urbano e de sua utilização pelos usuários. Procura desenvolver projetos de melhorias e manutenção propondo soluções para a região, ao invés de simplesmente transferir o problema somente para a municipalidade.

Em função de sua localização estratégica e a grande oferta de serviços e empregos, o Itaim Bibi é considerado como uma das áreas com maior atração e geração de viagens do município. Diariamente são registradas aproximadamente 400 mil viagens internas à região, 800 mil viagens por dia com destino a outras regiões e outras 800 mil viagens por dia de viagens atraídas à região (Fonte: CET/SP - Áreas de Atração/Geração de Viagens, Vol. 2, 2003).

Através destes dados, podemos confirmar a vocação de uma região de alta atração e geração de movimentos pendulares na cidade de São Paulo. Localizada na região do extremo leste da cidade, distante aproximadamente $36 \mathrm{~km}$ da região central da cidade, o distrito do Itaim Paulista possui uma alta densidade populacional (18.673 hab./km²- fonte PMSP). Segundo os indicadores do Ministério do Trabalho (RAIS, 1997), 
o Distrito do Itaim Paulista abriga 0,2\% do número total de empregos do Município de São Paulo com pouca oferta de empregos e serviços.

Por possuir uma parcela de sua área ocupada por assentamentos clandestinos muitas vezes moradias construídas são constituídas por precária alvenaria, ocupando, em alguns casos, áreas de risco nas encostas dos cinco córregos que cortam o distrito.

Curiosamente, o traçado das vias de boa parte do distrito se distingue por acompanhar o movimento informal das ocupações habitacionais, formando um desenho irregular das áreas conforme as necessidades de acesso aos espaços ocupados.

Devido a sua localização periférica, a pouca oferta de empregos e sua alta densidade demográfica, o Itaim Paulista se caracteriza como uma região de geração de viagens do município. Diariamente são registradas aproximadamente 260 mil viagens por dia internas à região 432 mil viagens com destino a outras regiões (Fonte: CET/SP - Áreas de Atração/Geração de Viagens, Vol. 5, 2003).

\section{A POLITICA DO PLANO DIRETOR ESTRATÉGICO NA ÁREA DE MOBILIDADE E TRANSPORTES}

\section{O debate das questões da gestão urbana e dos transportes com o urbano e sua ocupação}

Apesar da atuação dos vários arquitetos e urbanistas no sentido de estudar maneiras para solucionar a crise urbana de mobilidade, o tema continua sendo o centro de grandes polêmicas. Quais as causas desta crise? Será que além da nefasta atuação do capital imobiliário, o grande vilão no discurso dos arquitetos e urbanistas, há outros elementos que podem ser apontados?

Considerando que o planejamento para a cidade de São Paulo se baseou na estruturação dos eixos de crescimento e de políticas públicas de zoneamento e mobilidade, como bem apontam Leme (1990), Feldman (2005) e Anelli (2011), que outros elementos poderíamos apontar para contribuir ao necessário debate sobre o planejamento brasileiro?

Um dos temas que muito influi diretamente na experiência urbana para o cidadão comum e continua com debates entre os especialistas é a mobilidade urbana.

Mas o que é mobilidade urbana?

"Por que não se diz transporte público?" Pergunta o arquiteto Paulo Mendes da Rocha, aqui numa expressão livre de seu pensamento em uma entrevista para a revista Móbile (CAU) de junho de 2014, a qual o próprio nos responde com uma questão intrínseca:

Nada se mexe mais do que o universo urbano. Suponhamos que fiquemos dias, numa experiência absurda, sem ninguém sair de casa. Não houve, então, mobilidade urbana. É uma expressão ampla, uma forma de abordar uma questão sem dizer nada (MENDES DA ROCHA, 2014).

Procurando respaldar legalmente as definições de mobilidade e transporte, encontramos na Lei nº 12.587/12, Lei da Política Nacional de Mobilidade Urbana, no seu artigo 4, incisos I e II, a definição para transporte e mobilidade urbana, conforme para seus fins:

"I - Transporte urbano: conjunto de modos e serviços de transporte público e privados utilizados para o deslocamento de pessoas e cargas nas cidades integrantes da Política Nacional de Mobilidade Urbana;"

"II - Mobilidade urbana: condição em que se realizam os deslocamentos de pessoas e cargas no espaço urbano;" 
Realizando uma atenta leitura das lucubrações de Paulo M. da Rocha e das definições legais acima, podemos nos atrever a compor a idéia de que o transporte público urbano deveria ser uma questão direta e fundamental na vida das pessoas, enquanto que a mobilidade urbana deveria ser uma prioridade nos projetos urbanos da cidade.

Já durante as reuniões da subcomissão da questão urbana e dos transportes na Assembléia Nacional Constituinte de 1988 eram debatidos quais seriam as medidas que o estado e os municípios deveriam tomar para melhorar a gestão das cidades. Uma das premissas seria o desenvolvimento e aplicação de uma gestão democrática, isto é, a participação popular e o acesso às informações nas decisões de planejamento das cidades. A preocupação da subcomissão da questão urbana e dos transportes na Assembléia Nacional Constituinte de 1988 foi criar os mecanismos institucionais que garantissem que as políticas públicas e os investimentos públicos priorizassem o atendimento das áreas mais carentes de infraestrutura urbana e moradia.

Voltado para a questão da mobilidade urbana, o debate na constituinte visou atribuir, ao poder público, instrumentos para a elaboração de um plano de controle do uso e ocupação do solo, racionalizando a ocupação para melhorar a mobilidade e o transporte nas cidades.

A Constituição de 1988, nos seus artigos 158 e 159, prevê o aumento da participação dos municípios na receita fiscal distribuída visando aumentar também a capacidade local em empreender políticas públicas adequadas às necessidades dos municípios, bem como controlar a capacidade do poder público local em gerir de modo mais eficiente os seus espaços públicos.

O tema da mobilidade, mais do que um problema técnico atual, sempre entrou nas questões dos direitos fundamentais à cidade. O assunto sempre foi tratado, ainda que em diferentes épocas, por muitos arquitetos-urbanistas ativistas dos direitos urbanos como Ermínia Maricato (1995) ou Nabil Bonduki (2011). O debate recai sobre a mesma questão: a centralidade do problema da mobilidade foi a procura da defesa de uma premissa, nem sempre encontrada, no que tange o tema da mobilidade urbana. A problemática da mobilidade atinge todas as classes sociais, sendo o reflexo direto da organização ou desorganização da cidade, que expõe as longas distancias existentes entre a moradia, o estudo, o trabalho e a procura dos serviços. Mas, mais que isso, o sentido da universalização da mobilidade significa o direito de acessar a cidade.

Ora, a política financeira da questão urbana é uma das responsáveis pelo processo estratificado dos investimentos urbanos na cidade e, consequentemente, passa por um processo de urbanização estratificado. Se avaliarmos apenas um elemento básico da ocupação do solo, o transporte, sem uma visão da gestão espacial, de uma gestão urbana e de uma gestão da cidade, como um conceito interligado, terá uma estratificação da mobilidade urbana e consequentemente uma estratificação do setor habitacional.

A elaboração de um Plano Diretor que contenha uma nova política de uso e ocupação do solo e com diretrizes inovadoras visando a relação da mobilidade na cidade, podendo objetivar uma racionalização do crescimento e ajudar nas necessidades dos métodos de deslocamentos, pode atender a uma relação da mobilidade e seus meios incentivados em direção a uma ocupação urbana planejada.

Através de instrumentos urbanísticos definidos pelo Estatuto da Cidade, Lei nº 10.257/11 que regulamenta os capítulos de política urbana, o propósito da implantação de um Plano Diretor é organizar e ordenar o espaço urbano atual direcionando o futuro crescimento das cidades. Como instrumento legal, o plano diretor deve fornecer as diretrizes de orientação para o crescimento e o desenvolvimento urbano da cidade.

Um Plano Diretor Estratégico, como Lei, deve garantir o desenvolvimento da cidade de maneira que haja um planejamento com o controle das ações de políticas públicas, visando melhorar a qualidade de vida na cidade através da universalização do direito de acesso à cidade. Deve, ainda, possuir a faculdade de agregarse à iniciativa privada, para que suceda uma concordância de ações visando minimizar as necessidades coletivas da população. 
A Lei Municipal no 16.050, aprovada e sancionada em 31 de julho de 2014, regulamenta o novo Plano Diretor Estratégico da cidade de São Paulo, através da revisão do Plano Diretor aprovado em 2002.

A partir da publicação do novo Plano Diretor da cidade de São Paulo, os arquitetos e urbanistas possuem instrumentos para atuar na ordenação do crescimento da cidade e condições de analisar as novas estratégias para o desenvolvimento e da mobilidade da cidade contidas no documento.

\section{A ordenação territorial com a política de descentralização com a implantação de Pólos Estratégicos}

Uma das diretrizes do novo PDE de São Paulo estabelece como meta para a questão da moradia e da mobilidade urbana, o aumento no potencial de construção para novos empreendimentos, junto a corredores de transporte público coletivo existente e a construir, visando ampliar a oferta de habitação nas áreas envoltórias desses corredores. Para tanto, propõe que a organização da ocupação da cidade se baseie nos chamados Eixos de Estruturação da Transformação Urbana. Esta ação visa determinar uma ordenação diferenciada do uso e ocupação do solo nas áreas envoltórias das redes de transporte público, aumentando consideravelmente a densidade de ocupação em áreas especificas.

Como complemento das ações propostas, o Plano Diretor também prevê ações para expandir e aquilatar a rede de mobilidade urbana através de novas matrizes de deslocamentos. O objetivo é melhorar e tornar mais eficientes a integração e a articulação entre as várias modalidades de transportes, motorizados ou não.

Além do adensamento construtivo nas áreas envoltórias aos eixos de mobilidade, da ampliação da rede e da implementação de novas modalidades na mobilidade transportes urbanos, o novo Plano Diretor Estratégico objetiva uma redistribuição e uma reordenação das viagens da população pelo território através da criação de "Pólos Estratégicos de Desenvolvimento Econômico".

Conforme definido pelo artigo 177 do Plano Diretor de São Paulo:

Os Pólos Estratégicos de Desenvolvimento Econômico são setores situados em regiões de baixo nível de emprego e grande concentração populacional para a implantação de atividades econômicas, requerendo estímulos e ações planejadas do poder Público (PLANO DIRETOR DA CIDADE DE SÃO PAULO-ARTIGO 177).

Essa diretriz tem como meta deixar mais homogênea a oferta de empregos e serviços na cidade, aproximando os cidadãos que morem nas regiões mais extremas às novas ofertas de emprego.

Com essas diretrizes, o plano prevê que os futuros deslocamentos da população na cidade devam ocorrer no sentido das chamadas Áreas de Atração de Viagens. São assim denominadas devido à grande oferta de comércio e empregos que serão futuramente estimulados a se concentrar nessas áreas.

Para estimular a implantação de usos não residenciais e conseqüentemente estimular a oferta de empregos nas regiões mais distantes do centro, a municipalidade conjetura incentivos fiscais e regulamentações especiais nas áreas previstas para acolher esses pólos estratégicos.

Desse modo, o Plano Diretor mira induzir o crescimento da cidade com uma redistribuição mais equitativa das regiões da cidade que atraem e geram um maior número de viagens, contribuindo de forma a melhorar a mobilidade urbana. Assim, pretende-se diminuir a necessidade de deslocamentos pelo território, aproximando a moradia aos serviços e empregos.

Nabil Bonduki (2011, p.12), vereador responsável pela relatoria do novo Plano Diretor de São Paulo, explica a importância da criação de novas polaridades na cidade:

O desenvolvimento urbano das áreas periféricas, para que possam atrair atividades econômicas, exige uma qualificação urbanística e regulamentação fundiária, articuladas com programas de inclusão social e de economia solidária, capaz de estimular o empreendorismo na população local (BONDUKI, 2011, p.12).

Com implantação dos chamados novos pólos estratégicos, deverá haver um reestudo no planejamento 
no sentido de organizar e aparelhar as áreas escolhidas para que tenham condições e suporte para se amoldar aos benefícios e impactos do desenvolvimento local que acometerá os locais. Segundo instruídos no texto do Plano Diretor, serão escolhidos locais baseados em indicadores econômicos de determinadas áreas, levantamento dos modos de transporte público, serem próximos a locais de grande concentração de moradia e condições sociais dos moradores próximos, dentre outros aspectos.

Esses índices e parâmetros não foram estipulados neste momento e devem ser detalhados em legislação pertinente e especificada a partir da complementação e publicação de leis complementares.

Apesar de muitos estudiosos e urbanistas estudarem e debaterem a melhor forma de desenvolvimento para a cidade, desde a proposta do PUB no final da década de 1960 até o atual Plano Diretor de 2014, não parece ser uma tarefa muito simples o ato de desenvolver condições locais para a formação de novas centralidades urbanas.

\section{O PLANO DIRETOR ESTRATÉGICO DA CIDADE EASUA FORTUNA CRÍTICA:O CASO DAMOBILIDADE}

\section{A política de mobilidade}

O Plano Diretor Estratégico possui as diretrizes básicas para uma atuação urbanística coordenada capaz de responder aos desafios das questões da mobilidade urbana aliando processos participativos, descentralização econômica com estratégias de uso e ocupação do solo. O sucesso da requalificação do território dependerá, entretanto, de uma articulação institucional que favoreça a efetiva aplicação dos elementos definidos pelo planejamento urbano estratégico.

O Plano Diretor visa atender às necessidades da cidade combinando estratégias presentes nos planos predecessores e novas estratégias, principalmente no que diz respeito às transformações do uso do solo nas áreas de estruturação dos sistemas de mobilidade e nas definições de indicadores visando garantir um desenho urbano de melhor qualidade. Entretanto, as novas diretrizes adotadas no atual Plano Diretor da Cidade de São Paulo serão efetivas após aprovadas leis complementares e regulamentadas por decretos.

Voltando ao período de debates da Subcomissão da Questão Urbana e dos Transportes na Assembléia Nacional Constituinte de 1988, à época foi discutida amplamente a necessidade de planejar o processo de urbanização em longos prazos. Segundo as discussões ocorridas nos debates, com a participação dos constituintes, a elaboração e implantação de Planos Diretores deveriam prever um prazo de 20 a 30 anos, incluindo correções e assegurando um desenvolvimento ordenado da infraestrutura urbana e seus serviços correlatos. Quando da aprovação do Estatuto da Cidade, fixou-se em 10 anos o prazo de validade de um Plano Diretor.

A implementação do Plano Diretor atual não deve se resumir apenas na identificação e nos estudos dos problemas da cidade, mas de tratar as questões e resolver os problemas, no sentido de efetivamente implementar as políticas públicas projetadas que viabilizem a implementação de todas as diretrizes definidas no Plano.

A leitura do novo Plano Diretor da Cidade de São Paulo revela um conteúdo não tão inovador comparando-o com planos predecessores, entretanto, verifica-se uma ausência de referências no diagnóstico, não permitindo ao leitor maior compreensão.

\section{A ausência de diagnósticos e de estratégias: o PDE e a setorização}

O geógrafo e professor Milton Santos, em seu discurso na Subcomissão da Questão Urbana e dos Transportes na Assembléia Nacional da Constituinte de 1988, na sua 15a Reunião Ordinária, antecipou o futuro com o estimulo do debate de um problema social presente nos planos urbanísticos: 
Vou tocar em alguns pontos que vou enumerar: $1^{\circ}$ - Relação entre cidadania e território, à qual se ligará a falta de um discurso urbano e, paralelamente, abordarei a questão do valor do homem em relação ao lugar, os homens não valem apenas pelo que são, eles valem hoje, sobretudo, pelo lugar onde estão. E isso tem de ter uma resposta constitucional muito mais do que puramente legal (SANTOS, 1988, p.184).

(...) em outras palavras, um arranjo territorial desses bens e serviços de que, conforme sua hierarquia, os lugares sejam pontos de apoio, levando em conta a densidade demográfica e econômica da área e sua fluidez. Num território onde a localização dos serviços essenciais é deixada a simples lei do mercado, tudo colabora para que as desigualdades sociais aumentem. É o caso brasileiro atual (SANTOS, 1988, p.184).

Podemos extrair de sua fala argumentos com que possamos concordar ao afirmar que cabe ao poder público a distribuição no território municipal dos investimentos em infraestrutura urbana, serviços públicos e em edificações, visando a criação de mercados de trabalho para a população. Assim, procura-se estimular a distribuição de serviços e trabalhos onde a população mais precisa; próximo às suas moradias.

Deve-se assegurar uma distribuição mais justa da carga tributária correspondente aos investimentos públicos na cidade. Nesse sentido, há a necessidade da utilização do poder tributário como uma fonte de recursos na obtenção do conjunto dos investimentos onde há deficiência de urbanização. Os instrumentos de restrição ao direito de propriedade e o imposto progressivo junto aos instrumentos de transferência de potencial construtivo como a outorga onerosa e ao zoneamento especial possuem a capacidade de atender a estes objetivos.

Além de estimular a distribuição da população pelo território, o Plano Diretor também deve reconhecer a necessidade de estimular as economias locais de modo que os investimentos do município em infraestruturas e serviços locais sejam revertidos em economia local estruturando uma distribuição mais homogênea no espaço e mais diversificada nos distritos.

Uma ordenação do processo de urbanização da cidade requer um modelo de desenvolvimento coordenado. Os fatores econômicos e sociais deverão ser aplicados conjuntamente com o volume de investimentos urbanos, públicos e também privados, de acordo com a arrecadação municipal de impostos e investimentos. A distribuição espacial da população deverá ser condizente com a localização das unidades de produção econômicas que deverão proporcionar emprego e serviços à população.

Deve-se perceber a necessidade de um rearranjo planejado do território dos bens e serviços, levando-se em conta a densidade demográfica e atividades econômicas de uma área especifica, na qual deve haver uma repartição espacial desses bens e serviços, baseada no interesse público e que serviria de alavanca para novas atividades que por sua vez atrairiam outras novas atividades correlatas ou complementares.

O Plano Diretor Estratégico de 2014 para o Município de São Paulo aponta caminhos e prevê resultados para uma grande investida para a recuperação das funções da cidade a médio e longo prazos. O Plano Diretor é um plano extenso e sua aplicação dependerá da coalizão de interesses políticos, conciliando o desenvolvimento social e econômico da cidade. Embora o Estatuto da Cidade tenha definido os principais objetivos e intenções do planejamento brasileiro, isto é, o direito aos elementos básicos do urbanismo, moradia lazer, circulação e trabalho, nada garante ainda a universalização ou efetivação destes direitos.

Sendo assim, a função social da propriedade, o direito à moradia digna e a recuperação dos lucros imobiliários gerados à iniciativa privada através dos investimentos públicos continuam distantes apesar da ampla participação social no processo do planejamento.

O arquiteto-urbanista Flavio Villaça aponta haver uma confusão entre o que é atribuição dos planos diretores e o que é a transformação da cidade definida nos planos de governo. Para o autor a excessiva valorização do plano urbano é parte da cultura autoritária herdada do período ditatorial (1964-1986):

A falsa valorização dos planos urbanos se insere no contexto da supremacia do conhecimento técnico e cientifico como guia da ação política, ou seja, a ideologia da tecnocracia. Isto fica claro não só pela obrigatoriedade constitucional do Plano Diretor, mas também, pelo lado, pela desordem na exigência indiscriminada de planos por parte da legislação paulista e de outro pela falta de seriedade com que o poder público vem tratando os planos a décadas (VILLAÇA, 2005, p.21). 
A responsabilidade com o Plano Diretor é exatamente a de termos mecanismos institucionais que possam garantir a aplicação das diretrizes estabelecidas e, portanto, a sua continuidade através de diferentes "planos de governo".

Como ponto fundamental a ser tratado quando na efetiva implantação do Plano Diretor deve-se prever que, durante as discussões da legislação complementar ao plano, tivéssemos a preocupação de separarmos o que é matéria constitucional e o que seria matéria a ser tratada pelo legislativo, transformada em leis complementares e ordinárias. Na gestão da cidade, a ocupação desordenada dos espaços e o crescimento de ações visando uma mobilidade consciente, as instituições públicas devem por em prática as políticas do planejamento dos pólos estratégicos, promovendo o desenvolvimento econômico local, priorizando a valorização das populações e desenvolvendo suas funções sociais.

Deve-se definir uma política pública urbana formulada na base de uma estratégia visando usar os meios disponíveis com respeito às normas fixadas, e assim garantir a continuidade da aplicação do PDE no controle do desenvolvimento da cidade.

\section{UM PLANO DIRETOR PARA A CIDADE}

\section{O PDE e suas diretrizes}

O PDE deve regulamentar os demais instrumentos de planejamento para orientação de crescimento da cidade, principalmente no que tange o orçamento do município, pois é imprescindível que haja recursos financeiros suficientes destinados para a concretização das diretrizes traçadas.

Para melhor ilustrar a necessidade de uma melhor concepção de planejamento para a cidade, temos a valiosíssima contribuição de Dallari e Ferraz:

O plano diretor é o mais importante instrumento de planificação urbana previsto no Direito Brasileiro, sendo obrigatório para alguns Municípios e facultativo para outros; deve ser aprovado por lei e tem, entre outras prerrogativas, a condição de definir qual a função social a ser atingida pela propriedade urbana e de viabilizar a adoção dos demais instrumentos de implementação da política urbana [...] (Dallari e Ferraz 2006, p. 324).

Uma das principais questões a superar seus obstáculos diz respeito à compatibilização da situação econômica e financeira dos cofres públicos com as questões políticas das gestões públicas. Requer uma habilidade dos técnicos em equilibrar os diferentes interesses que cada um representa na melhor forma de atuação para a cidade, garantindo a efetiva aplicação dos recursos para o bem da cidade.

Esse é um dos maiores desafios da administração pública no destino dos recursos na área do planejamento urbano da cidade. Suas competências devem atuar no sentido de atualizar as diretrizes que o PDE, como Lei que é, de prever, levantar e aplicar os recursos necessários nas obrigações determinadas e no período temporal que foi imposto.

É constante a preocupação com o desempenho das finanças e suas receitas, a qual nem sempre anda em compasso com as necessidades da cidade e de seus habitantes. Com as despesas descritas e impostas por uma legislação e que se impõe a realizar e sem ter uma previsão orçamentária para esses investimentos, podem acarretar, quando investidos indevidamente, em endividamentos públicos. Peguemos, como exemplo, o que ocorre usualmente com as obras previstas para os corredores de ônibus na cidade. Nem se iniciaram ou as que se iniciaram estão sendo paralisadas por falta de recursos públicos, pois os recursos destinados para as obras são vultosos e foram fixados pelo próprio PDE. São obrigatórios, pois estão grafados no plano, mas o governo muitas vezes não possui recursos disponíveis.

Considerando que tais questões devem ter importância significativa no município, reproduzindo particularidades, é evidente que a metodologia de elaboração de um plano que não se vincule a determinações financeiras e orçamentárias, jurídicas e políticas. Uma omissão do PDE é o não é acompanhamento de qualquer planilha com estimativa de custos das obras e serviços listados para serem realizados. Esse fato 
poderia comprometer o orçamento de uma gestão pelo simples fato de que o que está listado em suas determinações, são obrigações, já que o Plano Diretor é e tem a força de Lei e, portanto, se faz obrigatório o que ali foi determinado.

Nesta mesma linha, o PDE também estabelece um período estimado para a execução das obras e serviços listados. Ora, a execução de obras, se houver orçamento para tal, leva meses ou até anos para ser concluída. Nesta mesma linha, temos que o Plano Diretor é uma ferramenta legal de planejamento urbano a ser aplicado a médio e longo prazo, e que necessariamente irá percorrer o mandato de vários prefeitos. Nestes casos, é necessária a aprovação orçamentária para que cada responsável aplique de maneira legal e justa os provimentos daquele ano. E sabemos que cada prefeito, que cada administração, possui suas prioridades e metas a alcançar.

Vê-se claramente que o PDE impõe dispositivos legais para suas realizações que podem, e irão, de contra ao que realmente as administrações podem realizar. Um contrassenso na avaliação dentro da elaboração de um planejamento para a cidade. O PDE, que tem em vista o melhor para a cidade, ao mesmo tempo pode depor contra ela mesma. O surgimento de detalhes não ponderados e previstos, pode colocar todo um planejamento a perder, por questões legais de impedimento.

A grande maioria dos artigos é formada por termos generalizados, como "incentivos", "prevê", "orienta", etc. São princípios muito gerais para uma Lei. Não definem parâmetros, e só servem para duplas interpretações do texto, dependendo do interessado. Podemos até nos exacerbar na colocação, mas o texto é genérico demais para ser considerado uma Lei. São diversas ações enunciadas e sem apontar os responsáveis por suas execuções.

O PDE, então, é apenas uma legislação de generalidades, e com a necessidade implícita de complementação e legalidade através de leis complementares. São os casos, por exemplo, da Lei de Zoneamento e do novo Código de Obras. É um instrumento que praticamente existe na prática, mas não de fato.

O arquiteto-urbanista Flavio Villaça, em duas ocasiões, assim se expressou sobre Planos Diretores:

Os planos são uma clara manifestação da força da ideologia da tecnocracia que ainda perdura entre nós. A fé no poder miraculoso dos planos tem sua origem no discurso competente e na tecnocracia que se alojou na esfera da administração municipal brasileira, mais que em qualquer outra esfera de governo (VILLAÇA, 1997, p.10).

Freqüentemente o Plano Diretor é apresentado como o guardião do futuro da cidade, o instrumento que vai apontar os rumos da cidade (VILLAÇA, 2005, p.8).

\section{A Descentralização dos Centros Atrativos e a Mobilidade Urbana}

Para entendermos a dinâmica da mobilidade urbana na cidade de São Paulo, temos que analisar mais detalhadamente as relações entre o uso e ocupação do solo urbano, os sistemas de transportes públicos e particulares, a infraestrutura viária e os fatores humanos.

Podemos verificar um grande aumento do grau e da extensão das áreas de deterioração do trânsito e do transporte público na cidade, o que acaba contribuindo para uma degradação urbana cada vez mais sentida no dia a dia de quem usa a modesta infraestrutura viária.

A origem da crise de mobilidade passa por uma ruptura entre as diversas políticas de uso do solo, do transporte público e o trânsito. Mesmo não documentados em procedimentos internos à gestão pública, percebe-se a sucessão de ações desastrosas e omissões do poder público com relação a uma pragmática e efetiva ação para dirimir e resolver os problemas da mobilidade.

Por uma simples observação dos mapas de crescimento da cidade, notamos que a população tende a fixar sua habitação na direção do extremo leste da cidade e, na contramão, os atuais pólos geradores de empregos e serviços avançam cada vez mais para o centro e para a região sudoeste da cidade. 
Um plano diretor que contenha uma política de uso e ocupação do solo sensato pode dar um redirecionamento na racionalização das necessidades de deslocamentos pela cidade, seja pelo transporte público ou privado motorizado ou mesmo pelos meios não motorizados.

A implantação de descentralização do consolidado centro polarizado, previsto pelo atual PDE na cidade de São Paulo, deve ser precedida, entre outros estudos, pela análise do impacto viário resultantes dos futuros pólos planejados ou áreas estratégicas, e por medidas mitigadoras a serem adotadas, visando garantir os novos padrões adequados de circulação viária que irão surgir.

A análise destes impactos pode ser contabilizada, ao seu término, na forma de um crédito indiretamente imposto ao munícipe ao se utilizar da malha viária diretamente afetada. Este crédito deve-se materializar, basicamente, no decréscimo de tempo de percurso e na diminuição operacional dos veículos em circulação.

Para amenizar este impacto e reduzir os custos coletivos, eliminando-os quando possível, o poder público deveria alocar os custos mais equitativamente associando-os ao uso de cada centro em vez de socializá-lo para todos os públicos afetados, direta e indiretamente. Deve-se priorizar a implantação dos futuros centros junto às linhas de metrô, corredores de ônibus implantados e a implantar e porque não, juntos a vias de grande circulação de veículos.

O poder público deverá investir e possuir o controle desse sistema, regulamentando e garantindo a aplicação dos recursos para as finalidades previstas ao público usuário. O interessado privado poderá fazer parte desse processo, mas o controle deverá ser rigoroso para que não haja a possibilidade de cometermos erros, como o de permitir a especulação imobiliária ditando as regras dentro das políticas públicas e no mercado imobiliário, principalmente para as habitações voltadas para as camadas da população de mais baixa renda.

Os empreendedores poderão fazer parte deste processo, apenas como parceiros na aquisição dos espaços e na implantação e utilização dos serviços e comércios, praticando uma gestão política público-privada. O empreendedor deverá participar com sua parcela através de custo direto, representado por obras de melhorias viárias através da implantação de sinalização viária (horizontal, vertical e semafórica) e ajustes de geometria viária, solicitadas pelos órgãos competentes.

A determinação da relação entre os dois custos citados acima, o direto e o indireto, com o valor agregado do investimento do poder público e do empreendedor, relacionado com as obras de implantação dos pólos estratégicos, geram injustiças quanto à forma de se determinar o real impacto causado pelo empreendimento, o raio de alcance deste impacto com as medidas mitigadoras imputadas.

Ainda, se as melhorias viárias implantadas realmente minimizam os impactos causados, ou não, após a implantação, pouco se terá onerado o empreendedor em relação ao custo social que este impõe ao município, ainda que se tenha a intenção de subestimar o valor do investimento. O fato é que uma parcela do custo social também é ressarcida pela entrada em atividade dos centros, através da geração de empregos diretos e indiretos. Mas ao que tange ao sistema viário, seus efeitos ainda deverão ser estimados com base em estudos futuros que tentam estabelecer o real impacto dos centros.

\section{Mobilidade é para todos?}

A cidade de São Paulo apresenta regiões que são ao mesmo tempo socialmente e territorialmente afastadas. Estão geralmente localizadas nas áreas mais periféricas e conseqüentemente apresentam uma categoria em que os moradores estão territorialmente e socialmente segregados na cidade.

Essa distinção dos habitantes no espaço não Ihes tira o direito à cidade. Toda a cidade deve ser vivenciada pelos seus cidadãos não só como proprietários dos locais em que vivem, mas tendo uma identificação com esses locais e fortalecendo suas raízes sociais com o espaço onde habitam. Na maioria das vezes, esse mesmo espaço é ocupado e caracterizado pelo convívio com pessoas de mesmas condições socioeconômicas, estabelecendo espaços fechados e isolando-os do resto do território. 
Se por um lado a intenção do PDE é incentivar a criação de empregos e serviços junto às moradias nas regiões mais periféricas da cidade através da implantação dos polos estratégicos, o próprio PDE poderá estar criando redutos espaciais e até mesmo redutos populacionais. Entenda-se por redutos espaciais, locais afastados dos centros, com suas populações específicas locadas em suas próprias regiões, provocando ações no sentido em que a população não "realize" mobilidade pelos demais espaços da cidade e também não interaja com a cidade como um todo.

A formação de pólos estratégicos, distribuídos estrategicamente pela cidade, caso de poli-centros, estruturando e consolidando os moradores nos seus próprios e específicos espaços à medida que os pólos são ampliados, só reforça e fortifica a presença em núcleos urbanos específicos não promovendo deslocamentos para outras áreas da cidade.

Deve haver uma ponderação nas considerações ao se interpretar o PDE no que diz respeito à questão da mobilidade nas áreas envoltórias dos pólos estratégicos. Deve-se prever uma rede de transporte eficiente ligada à cidade como um todo, não permitindo uma estratificação da sociedade nos seus próprios locais de moradia. Quando a mobilidade não é incentivada, estimulada e aplicada na cidade, há um caminho natural para intensificar as ações que resultam em separação sócio-espacial da população.

Eduardo Vasconcellos (2001) ressalta que uma das definições para mobilidade pode ser o simples ato de movimentar-se em uma combinação de condições físicas e econômicas da população. Esta é uma compreensão em que ele estabelece para uma política de transporte em oferecer um número maior de quantidade e ofertas de meios de transporte.

Podemos considerar a importância ou insignificância da implantação dos pólos estratégicos nas regiões mais periféricas da cidade, quando há uma contribuição para um maior desenvolvimento regional de bens e serviços, associado a uma rede de transporte público, não previsto no PDE. Mas temos que ter uma preocupação: sobre o quanto serão efetivas as ações contribuindo para minimizar os problemas sócios econômicos dessas regiões, e correndo o risco da irresponsabilidade de acarretar uma descentralização em relação ao pleno direito à cidade.

\section{REFERÊNCIAS}

ANELLI, Renato. Plano e conformação da base da metrópole: rede de mobilidade paulistanas. Porto Alegre: Marca Visual, 2011.

ASSEMBLEIA Nacional Constituinte - Subcomissão da Questão Urbana e Transporte, 1987.

BONDUKI, Nabil. O modelo de desenvolvimento urbano de São Paulo precisa ser revertido. Estudos Avançados-USP, v.25, n.71, 2011.

BRITO, Fausto. O deslocamento da população brasileira para as metrópoles. Estud. av. vol.20 no.57 São Paulo Maio/agosto. 2006.

CAMARGO, P. F. C. et al. São Paulo 1975, crescimento e pobreza. São Paulo: Loyola, 1976.

CAMPOS FILHO, Cândido Malta. Reinvente seu bairro: caminhos para você participar do planejamento de sua cidade. São Paulo: Ed. $34,2003$.

CONSTITUIÇÃO da República Federativa do Brasil - Texto constitucional promulgado em 5 de outubro de 1988.

CARLOS, Ana Fani Alessandri. A (re)produção do espaço urbano. São Paulo: Edusp, 1994.

CARLOS, Ana Fani Alessandri. Espaço-tempo na metrópole: a fragmentação da vida cotidiana. São Paulo: Contexto, 2001.

CARVALHO, Sonia Nahas de. Políticas públicas em questão: a experiência do programa CURA. São Paulo: Perspectivas, 1985.

DALLARI, Adilson Abreu; FERRAZ, Sérgio. Estatuto da cidade: comentários à Lei Federal 10.257/2001. 2a Ed. São Paulo: Malheiros, 2006.

FELDEMAN, Sarah. Planejamento e zoneamento. São Paulo 1947 a 1972. São Paulo: EDUSP ,2005. 
http://www.prefeitura.sp.gov.br/cidade/secretarias/subprefeituras/subprefeituras/dados_demograficos.

Lei no 10.257 de 10 de julho de 2001 - O Estatuto da Cidade.

Lei nº 12.587 de 3 de janeiro de 2012 - Política Nacional de Mobilidade Urbana.

Lei no 16.050 de 31 de julho de 2014 - Plano Diretor Estratégico do Município de São Paulo.

LEFEBVRE, Henri. O direito à cidade. Tradução de Rubens Eduardo Frias. São Paulo: Editora Centauro, 2001.

LEME, Maria Cristina da Silva. Francisco Prestes Maia e o urbanismo como campo de conhecimento e de atuação profissional - Simpósio Temático: Percursos profissionais: Arquitetos e Urbanistas, a contribuição para a teoria e a prática no Brasil, 1920-1960, 2010.

LEME, Maria Cristina da Silva. (Re) Visão do plano de avenidas. Tese de doutorado. São Paulo, FAU-USP, 1990.

LUCCHESE, Maria Cecília. Curam-se Cidades: uma proposta urbanística da década de 70. Dissertação de mestrado - FAU-USP, 2004.

MARICATO, Ermínia. Metrópole na periferia do capitalismo: ilegalidade, desigualdade e violência. São Paulo: FAU-USP, 1995.

MICHELLY, Ramos de. Louis-Joseph Lebret e a SAGMACS: formação de um grupo de ação para o planejamento urbano no Brasil. 1. ed. São Paulo: Alameda Editorial/ FAPESP, 2013. 337p.

MENDES DA ROCHA, Paulo. Revista Móbile (CAU), 2014.

MOREIRA, Mauricio Renato Pina, DOURADO, Anísio Brasileiro de Freitas. A taxa de motorização nas cidades brasileiras e a questão da mobilidade urbana. $19^{\circ}$ Congresso Brasileiro de Transporte e Trânsito, Brasília/DF - 2013.

PASTERNAK, Suzana. Loteamentos irregulares no Município de São Paulo. Planejamento e política pública, n³4, jan. /jun., 2010.

RELATÓRIO 2014 - Operação horário de pico, 17a avaliação. Companhia de Engenharia de Tráfego-CET, S.P. - maio de 2015.

ROLNIK, Raquel, KLINTOWITZ, Danielle. (I) Mobilidade na cidade de São Paulo. Estud. av. vol.25 no.71 São Paulo Jan./Abr. 2011.

SANTAGADA, Salvatore. A situação social do Brasil nos anos 80. revistas.fee.tche.br - Capa - v. 17, n. 4 (1990).

SANTOS, Milton. A Urbanização Brasileira. São Paulo: Hucitec, 1993.

SANTOS, Milton. Metrópole corporativa fragmentada: O caso de São Paulo. São Paulo: Nobel, 1990.

SCARINGELLA, Roberto Salvador. A crise da mobilidade urbana em São Paulo. São Paulo: Perspect. vol.15 no.1 São Paulo Jan./mar. 2001.

SACHS, Céline. São Paulo: políticas públicas e habitação popular. São Paulo: EDUSP, 1999.

SILVA, Carlos Henrique Dantas da. Plano diretor: teoria e prática. São Paulo: Saraiva, 2008.

SILVA, José Afonso da. Direito urbanístico brasileiro. $5^{\text {a }}$ ed. rev. e atual. São Paulo: Malheiros, 2008.

VASCONCELLOS, Eduardo Alcântara. Transporte urbano, espaço e equidade: análise das políticas públicas. São Paulo: Annablume, 2001.

VILLAÇA, Flávio. Dilemas do plano diretor. 1997. Disponível em:<http://www.ongcidade.org/site/arquivos/artigos/dilemas436f9e94d59fb. pdf>. Acesso em: 28 fevereiro 2016.

VILLAÇA, Flávio. As ilusões do plano diretor. São Paulo: Edição do autor; 1ª edição, 2005.

NOTA DO EDITOR (*) O conteúdo do artigo e as imagens nele publicadas são de responsabilidade do(s) autor(es). 